\title{
Rationalising Lysozyme Amyloidosis: Insights from the Structure and Solution Dynamics of T70N Lysozyme
}

\author{
Russell J. K. Johnson', John Christodoulou', Mireille Dumoulin' \\ Gemma L. Caddy ${ }^{1}$, Marcos J. C. Alcocer ${ }^{2}$, Gareth J. Murtagh ${ }^{3}$ \\ Janet R. Kumita ${ }^{1}$, Göran Larsson ${ }^{4}$, Carol V. Robinson' ${ }^{1}$, David B. Archer ${ }^{3}$ \\ Ben Luisi ${ }^{5}$ and Christopher M. Dobson ${ }^{1 *}$
}

${ }^{1}$ Department of Chemistry University of Cambridge Lensfield Road, Cambridge CB2 $1 E W, U K$

${ }^{2}$ School of Biosciences, University of Nottingham, Sutton Bonington Campus, Loughborough LE12 5RD, UK

${ }^{3}$ School of Biology, University of Nottingham, University Park Nottingham NG7 2RD, UK

${ }^{4}$ Medical Biochemistry and Biophysics, Umeå University SE-901 87 Umeå, Sweden

${ }^{5}$ Department of Biochemistry University of Cambridge

80 Tennis Court Road Cambridge CB2 1GA, UK
T70N human lysozyme is the only known naturally occurring destabilised lysozyme variant that has not been detected in amyloid deposits in human patients. Its study and a comparison of its properties with those of the amyloidogenic variants of lysozyme is therefore important for understanding the determinants of amyloid disease. We report here the X-ray crystal structure and the solution dynamics of T70N lysozyme, as monitored by hydrogen/deuterium exchange and NMR relaxation experiments. The X-ray crystal structure shows that a substantial structural rearrangement results from the amino acid substitution, involving residues 45-51 and 68-75 in particular, and gives rise to a concomitant separation of these two loops of up to $6.5 \AA$. A marked decrease in the magnitudes of the generalised order parameter $\left(S^{2}\right)$ values of the amide nitrogen atom, for residues $70-74$, shows that the T70N substitution increases the flexibility of the peptide backbone around the site of mutation. Hydrogen/deuterium exchange protection factors measured by NMR spectroscopy were calculated for the T70N variant and the wild-type protein. The protection factors for many of backbone amide groups in the $\beta$-domain of the T70N variant are decreased relative to those in the wild-type protein, whereas those in the $\alpha$-domain display wild-type-like values. In pulse-labelled hydrogen/deuterium exchange experiments monitored by mass spectrometry, transient but locally cooperative unfolding of the $\beta$-domain of the T70N variant and the wild-type protein was observed, but at higher temperatures than for the amyloidogenic variants I56T and D67H. These findings reveal that such partial unfolding is an intrinsic property of the human lysozyme structure, and suggest that the readiness with which it occurs is a critical feature determining whether or not amyloid deposition occurs in vivo.

(C) 2005 Elsevier Ltd. All rights reserved.

Keywords: human lysozyme; protein folding; amyloid disease; NMR spectroscopy; protein structure

\section{Introduction}

Abbreviations used: BMG, buffered minimal glycerol; BMM, buffered minimal methanol; ESI, electrospray ionisation; H/D, hydrogen/deuterium exchange; HSQC, heteronuclear single quantum correlation; LDA, ligation during amplification; NOE, nuclear Overhauser effect; NOESY, NOE spectroscopy; PDB, Brookhaven protein data bank; RD, regeneration dextrose; RMSD, square-root of mean-square deviation; $S^{2}$, square of the generalised order parameter; TOCSY, total correlation spectroscopy; TOF, time-of-flight; TTR, transthyretin.

E-mail address of the corresponding author: cmd44@cam.ac.uk
A familial form of non-neuropathic amyloidosis is associated with mutations in the gene encoding the antibacterial protein lysozyme. ${ }^{1-3}$ In this molecular disease, deposition of pathogenic variant lysozyme molecules in the form of amyloid fibrils occurs in internal organs, notably the liver, spleen and kidneys. ${ }^{1-3}$ Lysozyme is a 130 residue protein whose structure is composed of an $\alpha$-domain (residues 1-40 and 83-130) and a $\beta$-domain (residues 41-82), between which lies the active site 
cleft. ${ }^{4}$ There are five known mutations in the human lysozyme gene that give rise to six variant proteins, I56T (Thr for Ile at position 56), F57I (Ile for Phe at position 57), W64R (Arg for Trp at position 64), D67H (His for Asp at position 67), T70N (Asn for Thr at position 70) and the double mutant F57I/T70N. ${ }^{1-3,5}$ The F57I and W64R proteins have been identified by DNA sequencing (F57I, W64R) and immunohistochemistry (W64R) but, unlike the I56T and $\mathrm{D} 67 \mathrm{H}$ variants have not been purified from tissues or biological fluids from patients carrying these mutations. ${ }^{2,3}$ Nevertheless, individuals carrying these genetic mutations have been found to develop amyloidosis, implying that the effects of the mutations are directly responsible for the disease. Of the naturally occurring mutational variants, only the $770 \mathrm{~N}$ variant has not been associated with amyloid deposits in vivo. ${ }^{2,6}$ The I56T, W64R and F57I mutations all affect residues at the interface between the $\alpha$ and $\beta$ domains, whereas the D67H and T70N mutations occur in the long loop of the $\beta$-domain. ${ }^{4}$ PCR amplification of the lysozyme gene has indicated that $5-6 \%$ of the population in Canada and the UK carry the T70N lysozyme allele; ${ }^{2,5}$ a similar prevalence of the $\mathrm{T} 70 \mathrm{~N}$ allele has been found in patients suffering from systemic amyloidosis in the UK. ${ }^{6}$ No amyloid deposits of T70N lysozyme, however, have yet been observed and no co-deposition of T70N lysozyme was detectable in a patient affected with immunoglobulin light chain amyloidosis. ${ }^{2,6}$

The formation of amyloid fibrils from lysozyme has been demonstrated to proceed in vitro through a nucleated mechanism, ${ }^{7,8}$ a common process in the formation of amyloid fibrils. $^{9-11}$ The native states of the I56T and D67H variants have been found to be destabilised significantly relative to wild-type lysozyme and therefore to be able to undergo transient partial unfolding, under conditions where the native state of the wild-type protein is essentially fully populated. ${ }^{8,12}$ The native states of these two variants are, therefore, in dynamic exchange with a low concentration of partially unfolded species. In these transient species, the $\beta$-domain and the C-helix are unfolded simultaneously, whereas the rest of the $\alpha$-domain largely maintains its native-like structure. It has been postulated that the partially unfolded lysozyme molecules can then undergo an initial self-association step through the unfolded $\beta$-domain and C-helix. ${ }^{12,13}$ Reorganisation of these species, probably involving the recruitment of more of the lysozyme sequence into $\beta$-sheet structure, and further association of partially unfolded lysozyme molecules leads to ordered aggregates, and eventually to well-defined fibrillar structures. $X$-ray fibre diffraction studies show that such lysozyme fibrils have the cross- $\beta$ structure that is characteristic of amyloid fibrils. ${ }^{7,14}$ Solubilisation of ex vivo fibrils of the $\mathrm{I} 56 \mathrm{~T}$ and $\mathrm{D} 67 \mathrm{H}$ variants have shown that the protein molecules are incorporated into fibrils without proteolysis or modification and with all the disulfide bonds intact. ${ }^{1,13}$
A critical population of at least partially unfolded molecules is thought to be a prerequisite for both the initial nucleation steps, and for growth and elongation of the lysozyme fibrils. Relatively facile, transient partial unfolding at $37^{\circ} \mathrm{C}$ has been observed for both the $\mathrm{I} 56 \mathrm{~T}$ and $\mathrm{D} 67 \mathrm{H}$ variants at $\mathrm{pH} 8 ;, 12$ however, no detectable population of partially unfolded species has been detected at this temperature and $\mathrm{pH}$ for the wild-type protein. 8,12 The ability to access such species under physiologically relevant conditions is a property common to both the I56T and D67H variants and is thought to be the primary origin of their amyloidogenic character, 8,12 rather than any differences in the intrinsic properties of the partially unfolded lysozymes or the specific structure of the proteins in their native states. ${ }^{8,12,15}$ Indeed, stabilisation of the native states of the I56T and $\mathrm{D} 67 \mathrm{H}$ variants using a camelid antibody fragment has proved to be highly effective in preventing both partial unfolding and fibril formation. 7,8

T70N lysozyme has been the subject of initial characterisation by biophysical and structural techniques. Stopped-flow fluorescence spectroscopy has shown that this variant unfolds three to four times faster than the wild-type protein, but refolds from a chemically denatured state with kinetics similar to those of the wild-type protein. ${ }^{6}$ Measurements under equilibrium conditions in the presence of chemical denaturants and studies of thermal unfolding have demonstrated that $T 70 \mathrm{~N}$ is destabilised significantly relative to the wild-type protein but to a lesser extent than the amyloidogenic lysozymes. ${ }^{6,8,13}$ No loss in cooperativity was detected in the native state of the T70N variant, and the protein was found to be enzymatically active and to have near-UV and far-UV CD spectra similar to those of the wild-type protein. ${ }^{6}$ We report here the crystal structure of T70N lysozyme at $2.5 \AA$ resolution, and a detailed characterisation of the native state dynamics by NMR and mass spectrometry. We describe the extent of partial unfolding of T70N and wild-type lysozymes at various temperatures, information that gives new insight into the structural transitions required for lysozyme amyloidosis.

\section{Results}

\section{X-ray crystal structure of T70N lysozyme}

T70N human lysozyme was crystallised as described in the Materials and Methods and the structure solved at $2.5 \AA$ resolution (Brookhaven Protein Data Bank (PDB) 1W08). The space group $\left(P 2{ }_{1} 22_{1}\right)$ was the same as that found for the wildtype protein (PDB 1JSF, 1LZ1 and 1REX); the crystallographic properties are listed in Table 1. The structure shows that the overall fold of the T70N variant is similar to that of wild-type lysozyme, although a limited rearrangement of the protein backbone is clearly evident in local regions 
Table 1. Table of crystallographic parameters for T70N lysozyme

\begin{tabular}{lc}
\hline A. Data collection & \\
Space group & $P 2{ }_{1}{ }_{1} 2_{1}$ \\
Cell dimensions & \\
$a(\AA)$ & 31.117 \\
$b(\AA)$ & 56.178 \\
$c(\AA)$ & 62.488 \\
No. crystals & 1 \\
No. measured reflections & 25,074 \\
No. independent reflections & 3529 \\
B. Refinement & 1043 \\
No. protein atoms & 88 \\
No. solvent atoms & 1 \\
No. heteroatoms & $2.5-41.89$ \\
Resolution $(\AA)$ & 95.08 \\
Completeness of data $(\%)$ & 0.18487 \\
$R$-factor & 0.26759 \\
$R_{\text {free }}$ & \\
RMSD from ideal & 0.016 \\
$\quad$ Bond lengths $(\AA)$ & 3.041 \\
Bond angles $(d e g)$. & 23.657 \\
Mean $B$ value $\left(\AA^{2}\right)$ &
\end{tabular}

of the $\beta$-domain. The global square-root of meansquare deviation (RMSD) of the $C^{\alpha}$ atoms from the wild-type structure (PDB 1JSF) is $0.71 \AA$. Part of the long loop of the $\beta$-domain (encompassing residues 68-75) and part of the first two strands of the $\beta$-sheet structure along with the adjoining short loop (residues 45-51) both move significantly from their positions in the wild-type structure, as shown in Figure 1, with a maximum deviation of $6.5 \AA$ for the oxygen atom of Pro71. A movement of the structure in this region was suggested in a recent study involving molecular dynamic simulations, ${ }^{6}$ although these loops were predicted to move towards each other, while in the crystal structure they are observed to move apart. These two regions pack against each other in the structure of the wildtype protein such that Arg50 and Ser51, for example, are within $4 \AA$ of Thr70 (PDB file 1JSF). Additionally, both regions form hydrogen bonds with Ser61 and Arg62. These findings show that the T70N mutation causes structural rearrangements in the region of residues 68-75, and that these are communicated directly to residues 45-51, and, through mutual interactions, with residues Ser61 and Arg62.

A plot of the observed deviation for $C^{\alpha}$ atoms against residue number (Figure 2) demonstrates that, in the crystal structure of T70N lysozyme, the rearrangements due to the mutation affects the residues that are observed to be perturbed also in the structure of the $\mathrm{D} 67 \mathrm{H}$ variant (PDB 1LYY); however, the rearrangement resulting from the T70N mutation encompasses fewer residues and its magnitude is less pronounced than that for the $\mathrm{D} 67 \mathrm{H}$ mutation. The maximum deviations for the $\mathrm{C}^{\alpha}$ atoms in T70N lysozyme relative to the wild-type protein are $4.29 \AA$ for Pro71 and $1.9 \AA$ for Gly48; for the $\mathrm{D} 67 \mathrm{H}$ variant the corresponding values are $9.62 \AA$ and $7.58 \AA$. Interestingly, the position of the $C^{\alpha}$ atom of residue 67 is not perturbed significantly in the structure of $\mathrm{D} 67 \mathrm{H}$, whereas residue 70 has a deviation of $7.09 \AA$.

Two side-chain hydrogen bonding networks have been identified that are presumed to stabilise the $\beta$-domain of wild-type human lysozyme. ${ }^{4}$ These networks are almost entirely disrupted by the backbone rearrangements in the $\mathrm{D} 67 \mathrm{H}$ variant. ${ }^{13}$ The analogous rearrangements in the T70N variant do not disrupt either of the hydrogen bonding networks significantly, although several individual hydrogen bonds are not formed in the T70N variant. For example, in $\mathrm{T} 70 \mathrm{~N}$ the side-chain of Asn70 flips out of the wild-type network and forms a hydrogen bond to the main-chain amide hydrogen atom of Gly72 but the rest of this network is conserved. In the second hydrogen bonding network, Pro71, Arg62 and Asn44 all adopt different conformations, leading to the loss of associated hydrogen bonds; however, the core of the network of interactions is otherwise conserved.

Comparison of the $\mathrm{D} 67 \mathrm{H}$ variant with wild-type lysozyme reveals that the structural perturbations of the native state are transmitted to the domain interface with the side-chain of Ile56 adopting an alternative rotameric state. ${ }^{13}$ This transmitted conformational change is not seen in the structure of the T70N variant. Instead, the side-chain of Ile56 adopts its wild-type position, whilst the side-chain of Ile59 adopts an alternative rotamer; this latter structural change does not occur in either the I56T or $\mathrm{D} 67 \mathrm{H}$ variant, where Ile59 adopts its wild-type configuration. Overall, therefore, the longer-range effects of the amino acid substitutions in the three variants differ in subtle ways, both from the wildtype protein and each other.

Several other features were identified in the electron density map of T70N lysozyme. A putative chloride ion binding site was identified near Asn70, in a position different from that of the chloride ions associated with the wild-type protein. The side-chain of Asn70 was orientated to form an intermolecular hydrogen bond with Asp102. The polypeptide backbone (in the long loop of the $\beta$-domain) forms several hydrogen bonds to other adjacent regions of the polypeptide backbone through ordered water molecules in the structure of the T70N variant. This network appears to act to stabilise a section of the protein structure that would otherwise be exposed to bulk solvent.

\section{Perturbations of the NMR spectra associated with the T70N substitution}

The ${ }^{1} \mathrm{H}$ and ${ }^{15} \mathrm{~N}$ NMR spectra of the T70N were assigned as described in Materials and Methods, and the chemical shifts of the backbone amide groups of T70N compared to those of the wild-type protein (Figure 3). This comparison confirms that the largest perturbations are clustered around the site of mutation, with an approximately equal distribution of resonances shifted upfield and downfield. Resonances of several residues involved in the wild-type hydrogen bonding networks, such 
(a)

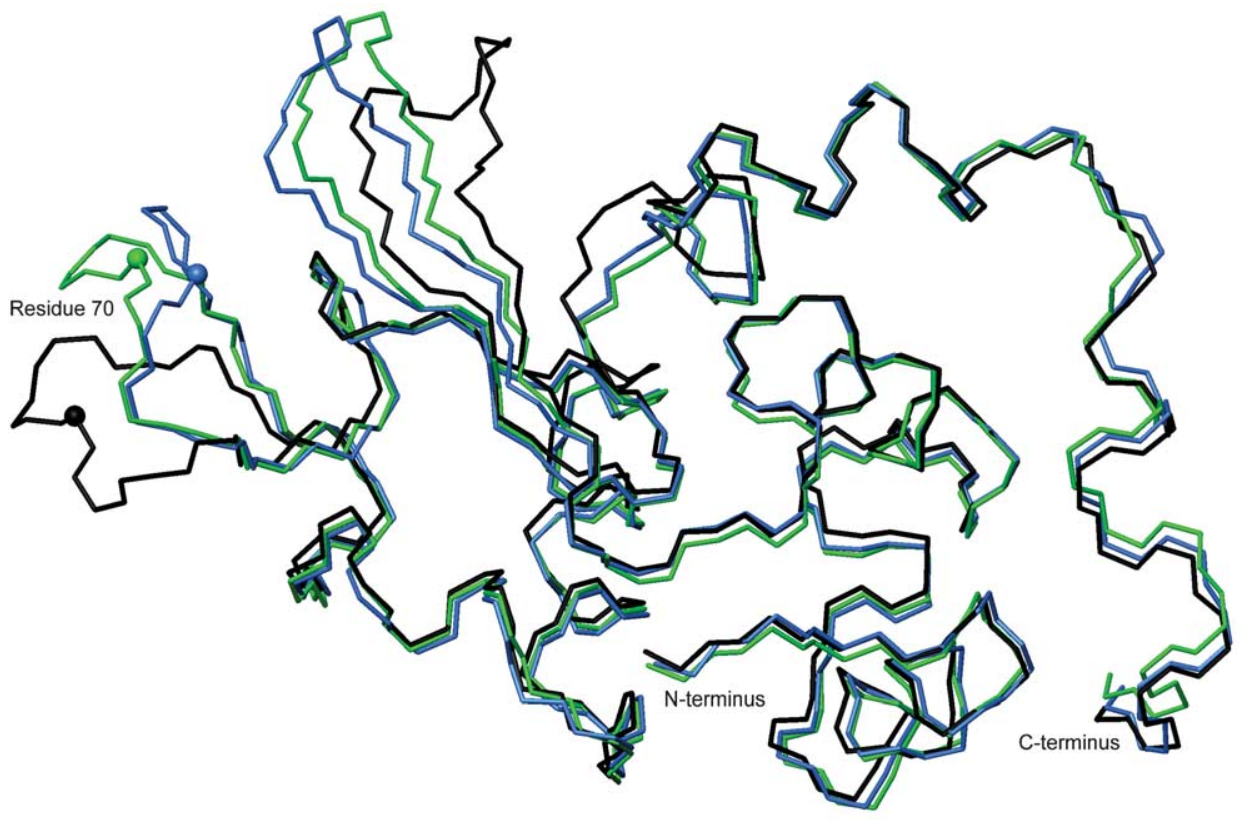

(b)

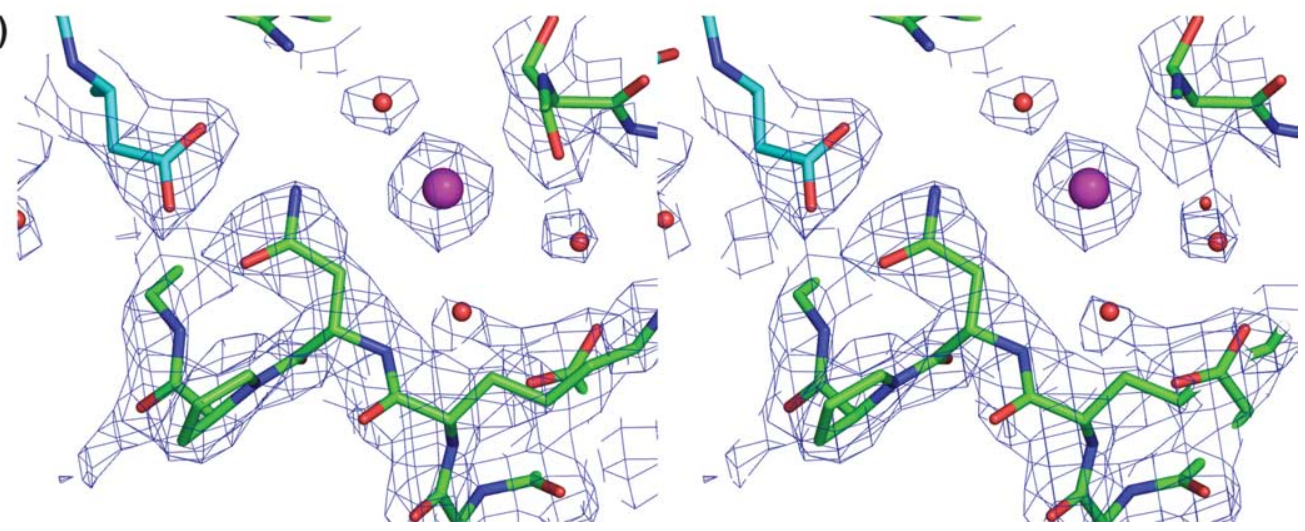

Figure 1. (a) Trace of $C, C^{\alpha}, N$ atoms from the X-ray structures of the T70N (green, PDB 1W08) and D67H (black, PDB 1LYY) lysozyme variants, overlaid onto the wild-type protein (blue, PDB 1JSF). The Figure was drawn with MOLMOL. ${ }^{38}$ (b) The site of the T70N mutation in the crystal structure of T70N human lysozyme shown in wall-eye stereo. The sidechain of Asn70 (central) is shown making hydrogen bonds to Pro71 and intermolecularly with Asp102, which is depicted in cyan as it originates from a neighbouring lysozyme molecule. The putative chloride ligand is depicted by a magenta sphere, and water molecules identified in the crystallographic structures are depicted as red spheres. The Figure was drawn with Pymol (Delano Scientific, San Carlos, CA, USA; http://pymol.sourceforge.net/).

as Thr52 and Asp67, show dramatic chemical shift changes; large chemical shift changes are not, however, limited solely to these residues, and almost all of the resonances of residues around the site of mutation exhibit a significant chemical shift.

The greatest perturbations in chemical shift occur for residues 50-52 and 59-79. These regions show considerable overlap with the deviations in atomic positions observed in the crystal structure, confirming that the structural rearrangement in solution is similar to that in the crystal. Importantly, the crystallographic evidence (Figure 2) suggests that not all the residues with perturbed chemical shifts are displaced significantly in the crystal structure; however, the chemical shift changes imply that there are subtle differences in the chemical environments of the amide groups concerned. Moreover, while there are no significant chemical shift changes associated with residues in the A and B helices, there are substantial perturbations for resonances arising from residues in the $\mathrm{C}$ and $\mathrm{D}$ helices, and the C-terminal $3_{10}$ helix. By contrast, several residues near the $C$ terminus of the protein exhibit relatively large deviations in their $C^{\alpha}$ positions from the wildtype protein, but minimal differences in chemical shifts (e.g. residues 120 and 129). It is expected that deviations in NMR chemical shifts would be associated with any changes in the solution structure. Hence, it is probable that at least some of the movements observed in the crystal structure near the $C$ terminus of the protein are caused by minor deformations of the protein structure in the crystal lattice. In support of this conclusion, this region of the protein in the crystal makes intermolecular contacts with the regions of the structure 


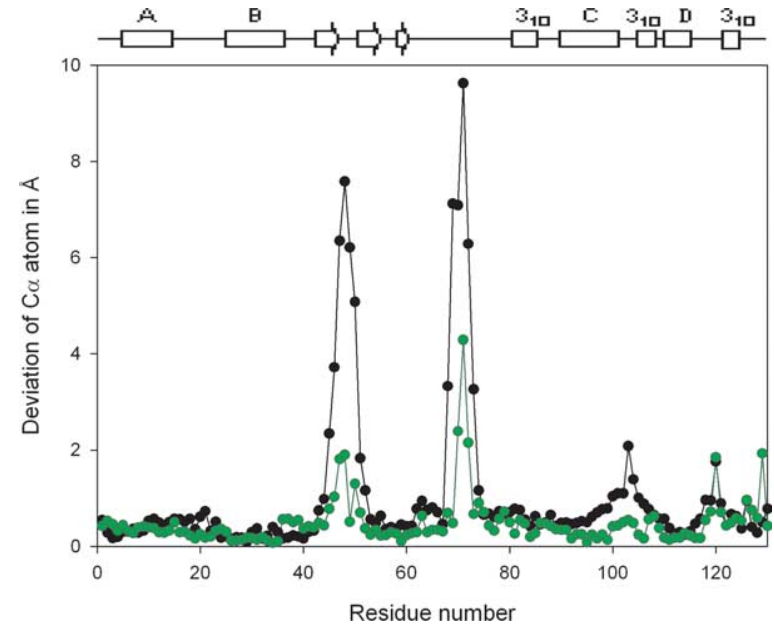

Figure 2. A comparison of the crystallographic $C^{\alpha}$ atom deviations for T70N (green, PDB 1W08) and D67H (black, PDB 1LYY) variants, from their positions in the wild-type protein (PDB 1JSF).
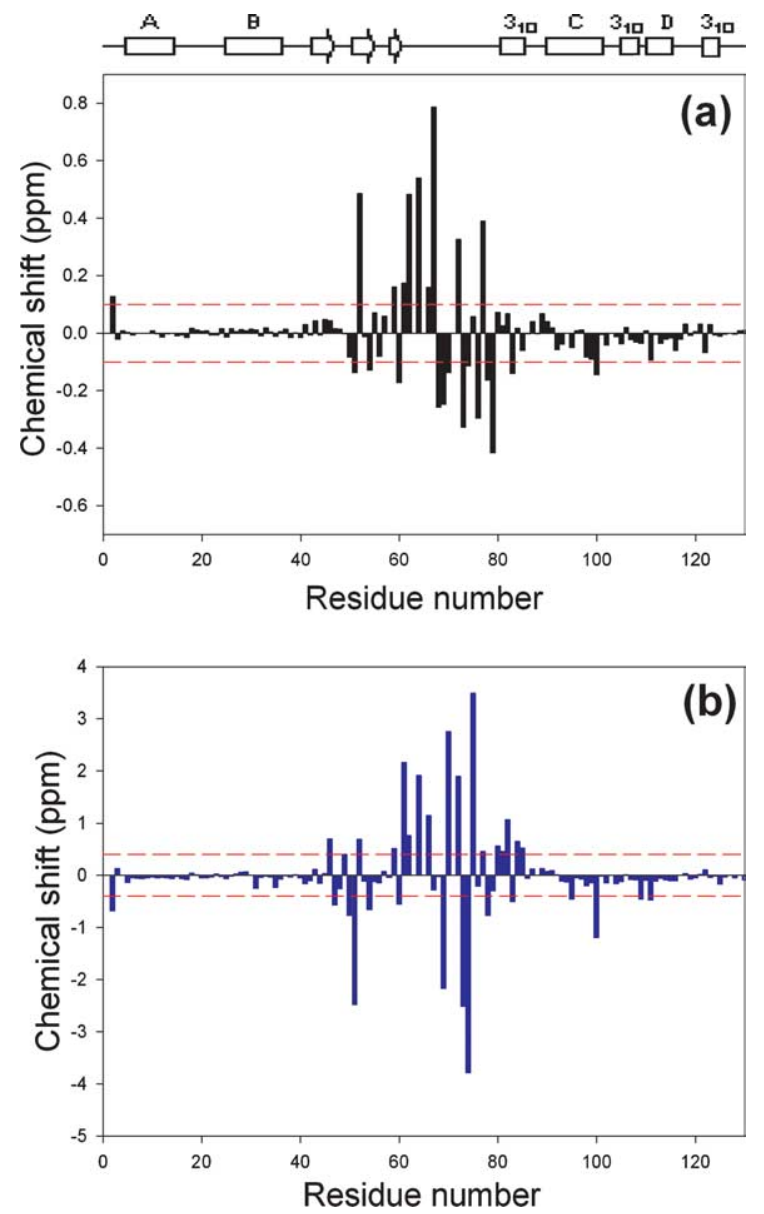

Figure 3. Perturbation in chemical shifts ((a) ${ }^{1} \mathrm{HN}$; (b) ${ }^{15} \mathrm{~N}$ ) for the T70N variant compared to the native wildtype lysozyme. Chemical shift changes of greater than $0.1 \mathrm{ppm}$ for ${ }^{1} \mathrm{H}$ and $0.4 \mathrm{ppm}$ for ${ }^{15} \mathrm{~N}$ are considered significant, and these boundaries are marked by broken red lines. that are perturbed substantially in the vicinity of the T70N mutation.

In contrast to the many changes in chemicals shifts associated with the T70N mutation, the NMR spectra of the I56T variant display few significant chemical shift changes relative to the wild-type protein, with only four residues having resonances whose chemical shifts differ by greater than $0.1 \mathrm{ppm}$ from the wild-type values. ${ }^{15}$ This observation is consistent with the very minor structural alterations in the crystal structure (PDB 1LOZ) found to accompany this mutation. All of these alterations occur spatially close to the site of mutation at the domain interface. Unlike the situation with the I56T variant, the D67H variant displays large chemical shift changes throughout much of the $\beta$-domain and interface region, with the greatest perturbations occurring for residues 48-52 and $60-82 .^{15}$ It is noteworthy that the resonances involved are approximately the same as those that are perturbed in the T70N variant.

\section{Thermal denaturation of the lysozyme variants followed by CD spectroscopy}

The stability of the I56T, T70N and wild-type proteins was studied by thermal unfolding, monitored by near-UV circular dichroism (CD). The unfolding transition for the $\mathrm{T} 70 \mathrm{~N}$ variant was observed to be $4.5( \pm 1) \mathrm{deg}$. C lower than that of the wild-type protein (Figure 4), with the I56T variant observed to unfold $10.5( \pm 1)$ deg. C lower than the wild-type. These results are in good agreement with those of previous studies, $6,8,13$ and demonstrate that T70N lysozyme is significantly destabilised (by nearly 5 deg. C) compared to the wild-type protein, but to a much lesser extent than the I56T and D67H variants, which both have transition temperatures approximately $10 \mathrm{deg}$. C lower than the wild-type protein. 8,13

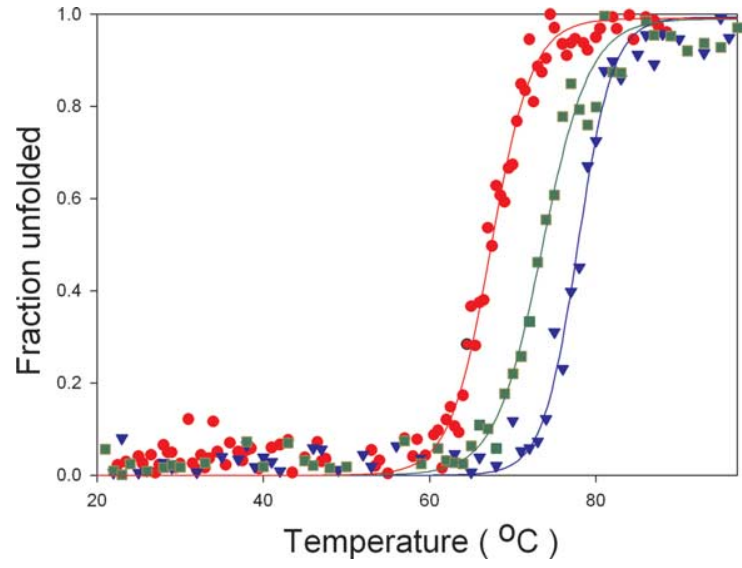

Figure 4. Thermal unfolding of wild-type (blue), I56T (red), and T70N lysozyme (green) monitored by CD at $270 \mathrm{~nm}$, displayed as the fraction of each protein that is unfolded, calculated on the basis of a two-state model. 


\section{Slow timescale fluctuations detected by hydrogen exchange}

The hydrogen/deuterium exchange (H/D) properties of T70N lysozyme were investigated initially using a pulse-labelling experiment monitored by mass spectrometry designed to detect any transient cooperative unfolding events. ${ }^{12}$ The fully deuterated protein was incubated at $\mathrm{pH} 8.0$ for various lengths of time, then exchange was quenched at low $\mathrm{pH}$ and low temperature, and the sample analysed immediately. The premise of this experiment is that, under appropriate conditions, the labile hydrogen atoms in a region of a protein molecule that unfolds cooperatively, even once during the labelling pulse, will be exchanged simultaneously and irreversibly at all solvent-exposed sites; this experiment therefore allows detection of partially unfolded intermediates even when they are present at only very low concentrations. The kinetics of hydrogen exchange are highly dependent upon solution conditions, and in order to identify unambiguously any differences between the variants and the wild-type protein, aliquots of two different proteins were subjected to exchange in the same solution. In order to separate the species in the mass spectrometer, one of the two proteins was uniformly labelled with the stable ${ }^{15} \mathrm{~N}$ isotope. Thus, a series of experiments was carried out at $37{ }^{\circ} \mathrm{C}$ with ${ }^{15} \mathrm{~N}$-labelled I56T lysozyme and unlabelled T70N lysozyme (Figure 5(a)). A second series of experiments was conducted at $47^{\circ} \mathrm{C}$ with unlabelled T70N lysozyme and ${ }^{15} \mathrm{~N}$-labelled wildtype protein (Figure 5(b)). A third series was conducted at $57{ }^{\circ} \mathrm{C}$ with the wild-type protein alone (Figure 5(c)). A clear bimodal distribution of masses, indicative of a locally cooperative partial unfolding process, was observed for peaks corresponding to the I56T variant at $37^{\circ} \mathrm{C}$; this behaviour is consistent with previous results, which demonstrate that partial unfolding of the $\beta$-domain and $C$ helix occurs under these conditions. ${ }^{8,12}$ In contrast, only a single set of peaks was observed for the T70N variant at $37^{\circ} \mathrm{C}$. These peaks decreased slowly in mass as a function of time in the labelling phase, illustrating that hydrogen exchange occurs via local fluctuations in structure that expose few amide groups to the solvent at any one time; rather than via the cooperative partial unfolding event that was detected for the I56T variant.

The hydrogen exchange behaviour of the T70N variant and ${ }^{15} \mathrm{~N}$-labelled wild-type lysozyme at $47^{\circ} \mathrm{C}$ (Figure 5(b)) shows a bimodal distribution of peaks for the $T 70 \mathrm{~N}$ variant, clearly indicating that partial unfolding occurs at this temperature. A single set of peaks is, however, still observed for the wild-type protein, showing that no cooperative partial unfolding is detectable for the wild-type protein at $47^{\circ} \mathrm{C}$ under the conditions used here. These results prove that the $\mathrm{T} 70 \mathrm{~N}$ variant populates significantly a transiently, partially unfolded state under conditions where the wild-type does not. This observation further suggests that the popu- lation of transiently, partially unfolded molecules for the T70N variant at $37^{\circ} \mathrm{C}$, is indeed too low to be detected by the H/D experiments carried out here, but it will be higher for the T70N variant than for the wild-type protein; although significantly lower than for the amyloidogenic variants.

Increasing the temperature to $57^{\circ} \mathrm{C}$, however, results in a clear bimodal distribution of peaks for the wild-type protein (Figure 5(c)); this result shows that it too can undergo cooperative partial unfolding at this higher temperature. Moreover, the mass differences suggest that the nature of the intermediate species being detected under the different conditions for the different proteins could be essentially the same. These observations, taken together, suggest that the ability to populate a partially unfolded state is an intrinsic property of human lysozyme rather than being a specific property of the amyloidogenic variants. Nevertheless, the mutations affect the dynamic equilibrium between the native and partially unfolded states, with the result that the latter are present at a significantly higher population in the amyloidogenic proteins, such that under physiological conditions they can dominate the aggregation behaviour that leads to the formation of amyloid fibrils. Moreover, the equilibrium between the native and partially unfolded states of the T70N variant can be seen to lie between that found for the amyloidogenic variants and for the wild-type protein.

The rates of H/D of individual labile amide hydrogen atoms for the T70N and wild-type protein were then determined at $37^{\circ} \mathrm{C}$ and pD 5 using NMR spectroscopy; from these rates, exchange protection factors were calculated as defined by the increase in protection over the rates for the same amide hydrogen atoms in an unstructured (random coil) state. ${ }^{19}$ High protection factors were found in both proteins for the amide hydrogen atoms in regions that correspond to elements of secondary structure in the native state (Figure 6(a)). Amides in the A, B, and $C$ helices, and in the core of the $\beta$-domain, show the greatest protection against exchange in both T70N and wild-type lysozymes. Amide groups of residues in the $\mathrm{A}$ and $\mathrm{B}$ helices in T70N have protection factors similar to those found in the same regions of the wild-type protein, but there are significant differences for amide groups in the core of the $\beta$-domain. All of the residues with amide hydrogen atoms showing a greater then tenfold increase in exchange rates as a consequence of the T70N mutation are located in the region of residues 39-84 (Figure 6(b)), which corresponds almost exactly to the $\beta$-domain. Interestingly, the greatest differences between wild-type lysozyme and the amyloidogenic variants are found in this region. This observation demonstrates clearly that, while the structural perturbations of the T70N variant observed in the crystal structure affect only residues spatially close to the site of mutation, the dynamic behaviour detected by hydrogen exchange is significantly altered for amide groups located in 
(a)

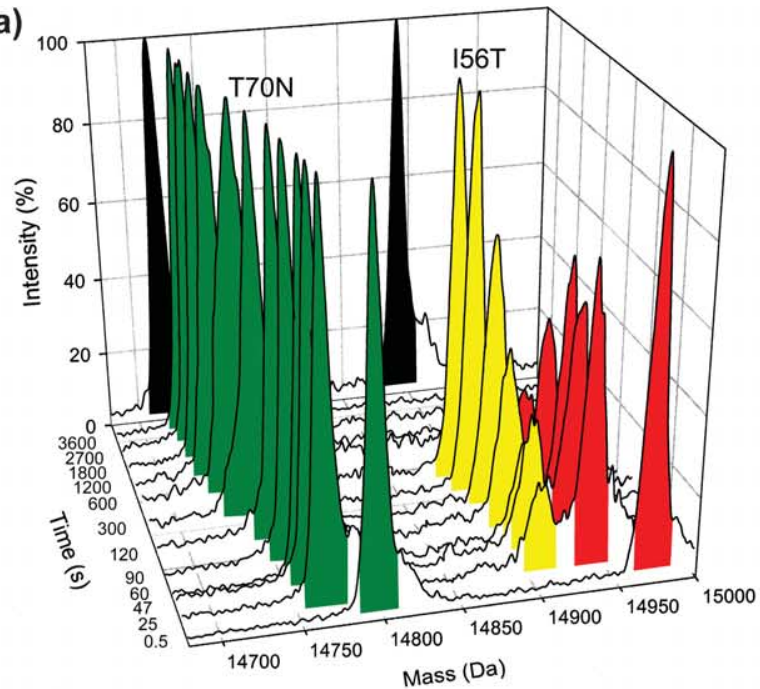

(b)

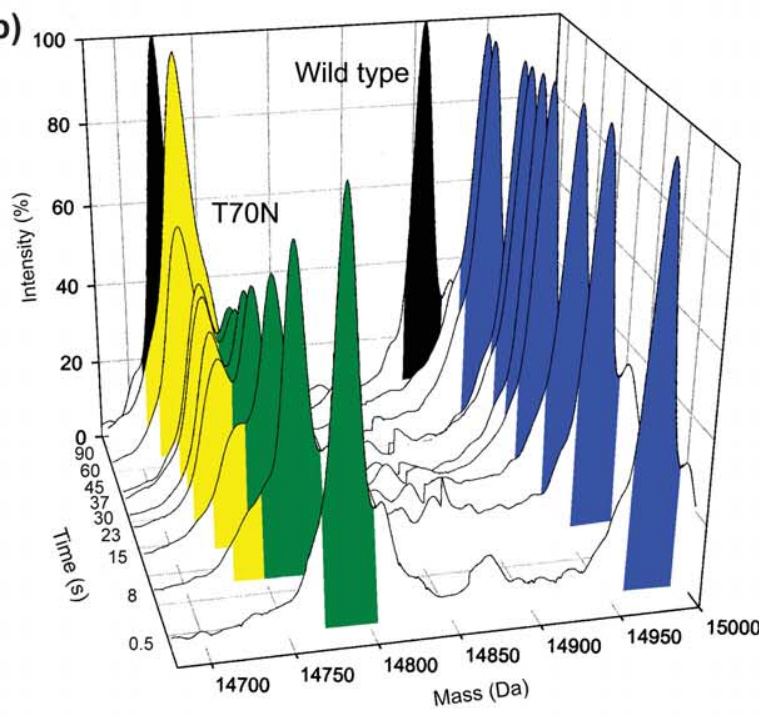

(c)

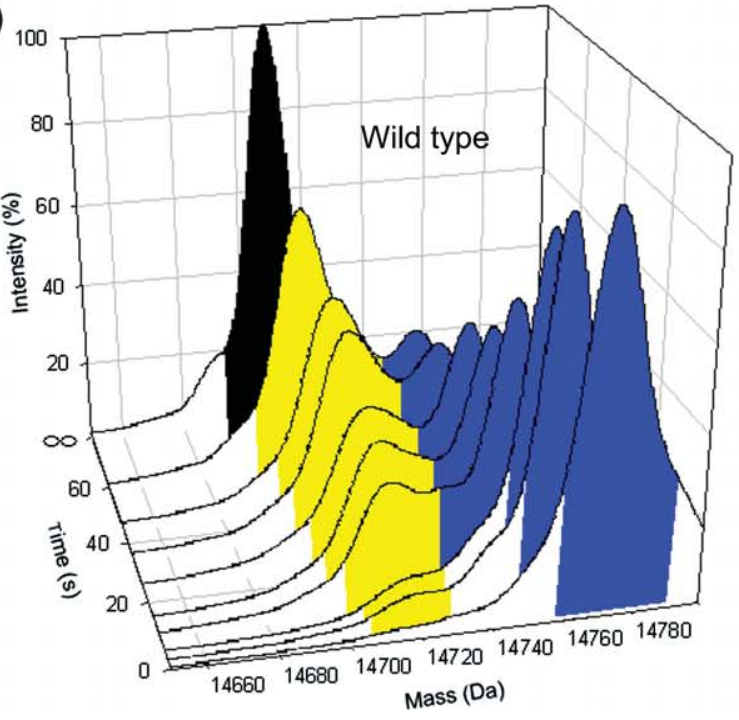

Figure 5. (a) H/D exchange of the T70N (green) and I56T (red/yellow) lysozyme variants monitored by electrospray mass spectrometry at $37^{\circ} \mathrm{C}$. The I56T variant displays a clear bimodal distribution of peaks indicative of locally cooperative partial unfolding. The T70N variant
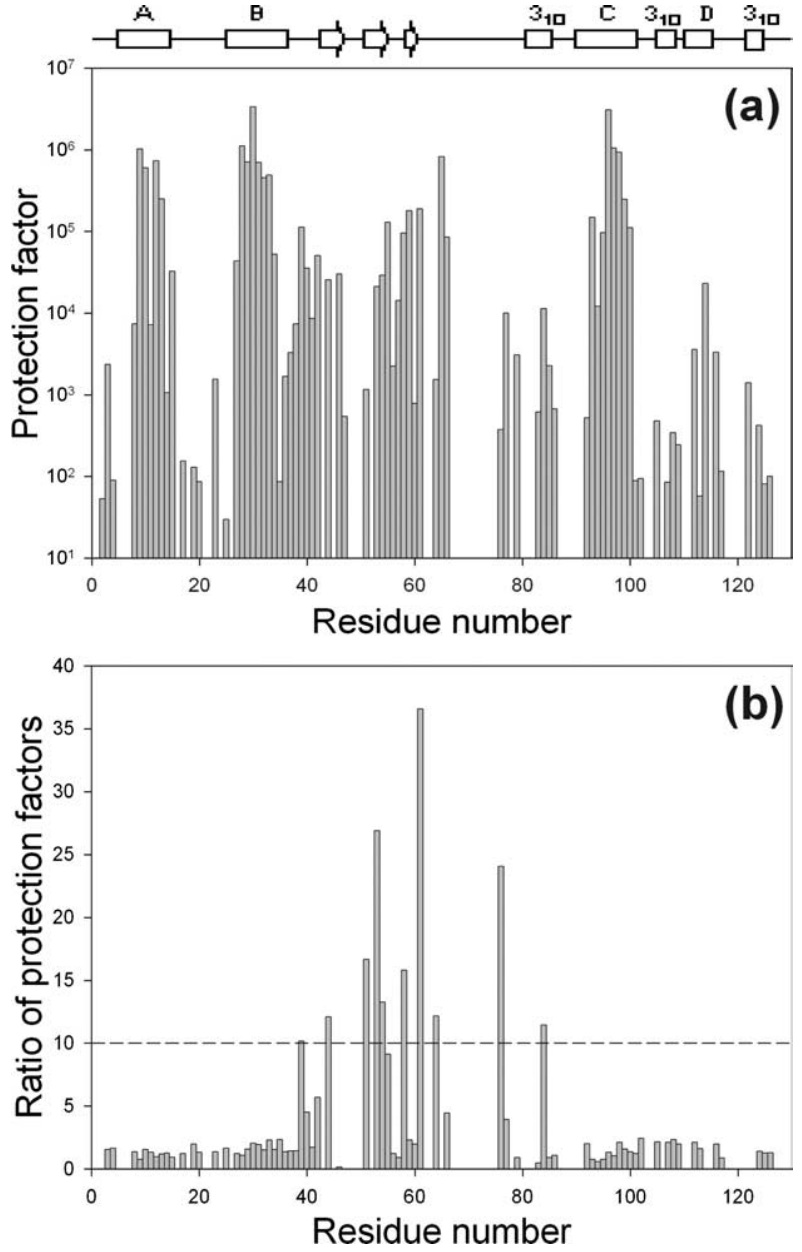

Figure 6. (a) Protection factors for the amide hydrogen atoms in the T70N variant, calculated from the rates of hydrogen exchange monitored by NMR. Residues for which the hydrogen exchange rates were too fast to be measured reliably are left blank. (b) Ratios of amide protection factors for the wild-type lysozyme compared to those for the T70N variant. The broken line represents the value for which amide groups of the wild-type protein have protection factors ten times those of the T70N variant. A ratio of 1.0 represents an equal degree of protection in both proteins.

shows a single peak decreasing in mass over time, indicative of exchange through uncorrelated local fluctuations (see the text). (b) H/D exchange of the T70N variant and wild-type lysozyme monitored by electrospray mass spectrometry at $47^{\circ} \mathrm{C}$. The bimodal distribution of peaks indicative of locally cooperative partial unfolding is clearly displayed for the T70N variant, whereas a single peak is observed for wild-type lysozyme, indicative of exchange occurring via local fluctuations of the native state. (c) H/D exchange of wild-type lysozyme monitored by electrospray mass spectrometry at $57^{\circ} \mathrm{C}$. The bimodal distribution of peaks indicative of the locally cooperative partial unfolding step is clearly evident at this temperature. 

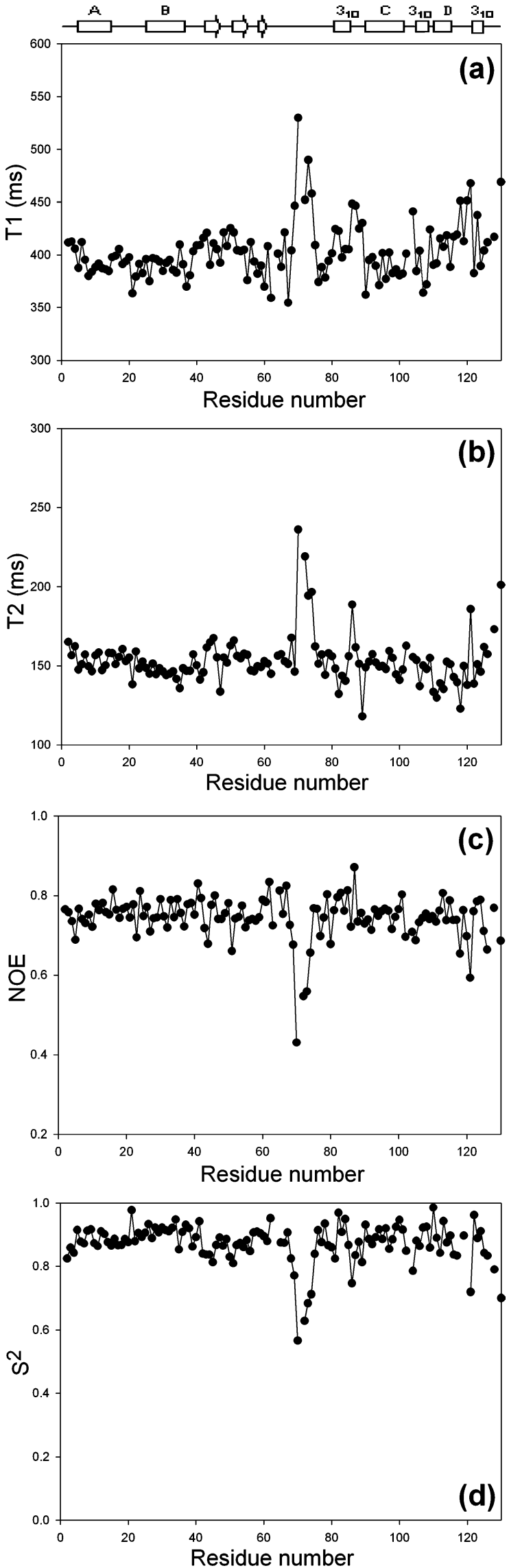

Figure $7 .{ }^{15} \mathrm{~N}$ NMR relaxation data for backbone amide groups of T70N lysozyme. (a) ${ }^{15} \mathrm{~N}$ spin-lattice relaxation much of the $\beta$-domain and $C$ helix. Thus, the dynamic behaviour is perturbed in some regions of the protein where the observed structural changes are very small. It is not clear, however, whether this increase in susceptibility to exchange caused by the mutation results from the great sensitivity of fluctuations in the protein backbone to small changes in structure, or the result of larger correlated changes in dynamic behaviour.

\section{Fast timescale dynamics from NMR relaxation measurements}

To investigate the dynamic properties of the T70N variant on the timescale of nanoseconds to picoseconds, a series of ${ }^{15} \mathrm{~N}$ NMR relaxation experiments were recorded $\left(T_{1}, T_{2}\right.$ and $\left\{{ }^{1} \mathrm{H}-{ }^{15} \mathrm{~N}\right\}$ nuclear Overhauser effect (NOE), Figure 7(a)-(d)). Relaxation data were obtained for 122 out of the 130 residues in the protein.

The most significant differences in the relaxation behaviour between the T70N variant and the wildtype protein are increases in the $T_{1}$ and $T_{2}$ relaxation times for residues 69-74, reflecting an increase in their fast timescale (picoseconds) dynamics (G.L. et al., unpublished results). ${ }^{17}$ Asn70, the residue introduced by the genetic mutation, was found to have the highest $T_{1}$ and $T_{2}$ values, $530( \pm 28) \mathrm{ms}$ and $236( \pm 6) \mathrm{ms}$, respectively, compared to the mean values of $402 \mathrm{~ms} \pm 3.8 \%$ and $154 \mathrm{~ms} \pm 1.8 \%$ for the $T_{1}$ and $T_{2}$ relaxation times. A decrease in the NOE effect was observed for the same residues, with Asn70 exhibiting the lowest NOE value of 0.43 , compared to an average of 0.74 for the $\mathrm{T} 70 \mathrm{~N}$ variant. In contrast, no decrease in the NOE effect is observed for residues 70-74 in the wild-type protein relative to other residues (G.L. et al., unpublished results). ${ }^{17}$ Ser51 is another interesting residue, as it has a slightly decreased NOE effect (0.66) in the T70N variant compared to wild-type lysozyme (0.80). Interestingly, a large reduction in $\mathrm{NOE}$ values is found in the $\mathrm{D} 67 \mathrm{H}$ variant for the adjacent residue Arg50 (0.40); however, Arg50 (0.78) in the T70N variant is actually higher than that found in the wild-type protein (0.71). These residues all reside on the two regions (residues 43-53 and 67-75) perturbed in the crystal structures of the D67H and T70N variants, and the differences in the NOE effects presumably result from changes in dynamic behaviour associated with the structural reorganisations.

The relaxation data were analysed according to a model-free formulism ${ }^{18-20}$ using the program Modelfree (version 4.15). ${ }^{21}$ Among other parameters, this analysis generates order parameters $\left(S^{2}\right)$, which reflect the local dynamics on a timescale of $<$ ca 200 ps. The data were fit to a model of

time constants $\left(T_{1}\right)$. (b) ${ }^{15} \mathrm{~N}$ spin-spin relaxation time constants $\left(T_{2}\right)$. (c) $\left\{{ }^{1} \mathrm{H}\right\}-{ }^{15} \mathrm{~N}$ heteronuclear NOE effects. (d) Generalised order parameters $\left(S^{2}\right)$. 
isotropic rotation with a rotational correlation time of $4.7( \pm 0.1) \mathrm{ns}$. These results show that, like the wild-type protein, T70N lysozyme is highly structured, with high order parameters (above 0.8) throughout most of the protein backbone (Figure $7(\mathrm{~d})$ ), and that the overall tumbling rate is essentially the same as for the wild-type protein (G.L. et al., unpublished results). ${ }^{17}$ Large decreases in order parameters relative to the wild-type protein are seen, however, for residues 69-74, as expected from the differences in relaxation times discussed above. Indeed, the $S^{2}$ values reach a minimum of 0.57 for Asn70, demonstrating clearly that the reorganisation in the vicinity of the mutation site results in greater flexibility of the peptide backbone. A similar decrease in order parameters has been observed for the $\mathrm{D} 67 \mathrm{H}$ variant; although the decrease was significantly greater in magnitude (G.L. et al., unpublished results).

\section{Aggregation kinetics}

The rates at which $156 \mathrm{~T}, \mathrm{~T} 70 \mathrm{~N}$ and wild-type lysozymes aggregate were measured by right-angle light-scattering, under specific conditions shown previously to be conducive to the formation of amyloid fibrils containing the full-length protein molecules (Figure 8). ${ }^{7}$ The kinetic profiles in each case show the existence of a lag phase followed by rapid growth, behaviour typical of a nucleated process and observed previously for the $\mathrm{D} 67 \mathrm{H}$ variant and many other similar amyloidogenic systems. ${ }^{7-11}$ Although the kinetics varied somewhat from one experiment to the next, a clear trend in the length of the lag phase and rate of aggregation (I56T > T70N > wild-type) emerged. Under the conditions used, the midpoints of the aggregation reaction are approximately: $556 \mathrm{~T}, 210( \pm 40) \mathrm{min}$; T70N, $750( \pm 175) \mathrm{min}$; and wild-type, $1500( \pm 250) \mathrm{min}$. Therefore, the rate of aggregation follows both the

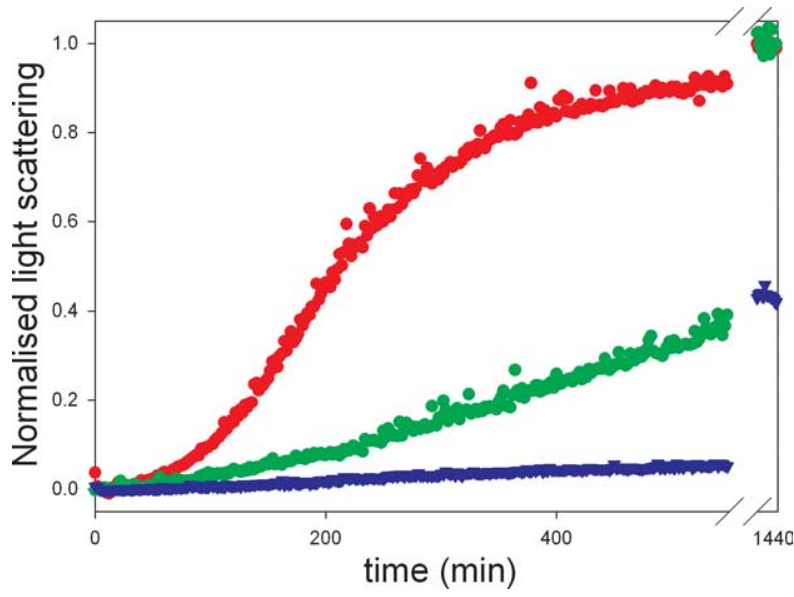

Figure 8. Aggregation of lysozyme monitored by rightangle light-scattering. The data represent the average of three experiments. Data for the I56T variant are shown in red, for T70N in green, and for the wild-type protein in blue. decrease in the native state stability of the variants, and the increase in the population of the partially unfolded states. This result shows that the T70N variant has a propensity to aggregate that is intermediate between the I56T/D67H variants and the wild-type protein.

\section{Discussion}

\section{Comparison of the structures of the T70N variant and wild-type lysozymes}

The overall structure of T70N lysozyme is very similar to that of the wild-type protein, except for some rearrangements in the $\beta$-domain in the vicinity of the mutation. These rearrangements are similar to those observed for the $\mathrm{D} 67 \mathrm{H}$ variant; however, in contrast to the $\mathrm{D} 67 \mathrm{H}$ variant, the sidechains in the $T 70 \mathrm{~N}$ variant are still able to form the core of the two side-chain hydrogen bonding networks found in the $\beta$-domain of the wild-type protein. The structural rearrangements in the vicinity of the T70N substitution are, therefore, not transmitted through the polypeptide chain to the interface between the $\alpha$ and $\beta$ domains, in the manner seen for the $\mathrm{D} 67 \mathrm{H}$ variant. The effects of the mutation on the native structure are restricted largely to residues that are spatially close in structure to Asn70. Long-range effects appear to be relatively minor; for example, the side-chain of Ile59 adopts an alternative rotamer in the T70N variant. The rearrangement in the native state of this variant does, however, provide an explanation for the measurable decrease in stability, as several stabilising hydrogen bonds present in the wild-type protein are not formed in the $T 70 \mathrm{~N}$ variant. Moreover, there are some slight differences in the packing of the side-chains of a number of residues in the interior of the protein, such as the side-chain of Ile59, which adopts an alternative rotameric state. Interestingly, the extent of the structural rearrangement in $T 70 \mathrm{~N}$ is intermediate between that observed in the $\mathrm{D} 67 \mathrm{H}$ variant and wild-type lysozyme, a result consistent with the intermediate thermostability of its native state.

The crystal structure of the I56T variant is essentially the same as that of the wild-type protein, strongly suggesting that a rearrangement of the native fold is not required for either the transient unfolding event or amyloid fibril formation; ${ }^{13}$ however, the ability of the $\mathrm{I} 56 \mathrm{~T}$ and $\mathrm{D} 67 \mathrm{H}$ variants to transiently populate a partially unfolded state can be rationalised as being the effect of the loss of interactions in the native state, either directly from the mutations or as a consequence of the associated conformational changes. Studies of a variety of proteins using site-directed mutagenesis have shown that amino acid substitutions affecting certain key residues can alter the rates of protein unfolding and refolding substantially, and thus perturb the equilibrium position between two states. $^{22,23}$ Interestingly, examination of all the 
known, disease-causing mutations in human lysozyme involve residues that form important longrange native interactions in the wild-type protein. Although the structures of the F57I and W64R variants have not been reported, it is clear that the side-chains introduced by the mutations have sufficiently different properties from those present in the wild-type protein that at least some of the wild-type interactions will be disrupted. Hence, the I56T, F57I and W64R mutations are known (I56T) or expected (F57I, W64R) to disrupt long-range hydrophobic interactions that bridge the $\alpha$ and $\beta$ domain interface. The $\mathrm{D} 67 \mathrm{H}$ mutation, on the other hand, perturbs the side-chain hydrogen bonding networks associated with the $\beta$-domain, and the resulting perturbations are transmitted through the protein to the region of the domain interface.

In both the amyloidogenic variants (I56T/D67H) of lysozyme studied in detail so far, the $\beta$-domain and domain interface region are perturbed substantially by the mutations. In contrast, the T70N mutation does not appear to perturb significantly the domain interface region or the hydrogen bonding networks in the $\beta$-domain. The greater disruption of stabilising interactions in the $\beta$-domain and the interface region, therefore, provides an explanation of the greater tendency of the $156 \mathrm{~T}$ and $\mathrm{D} 67 \mathrm{H}$ variants to populate a partially unfolded state, relative to the T70N variant and the wild-type protein. It should be noted, however, that the destabilising T70N mutation is located in the $\beta$-domain, i.e. in the region of the protein that unfolds in a locally cooperative manner. This observation raises the question of whether the position of mutation is intrinsically important for promoting amyloidogenicity. These results suggest that the propensity of a variant for partial unfolding is linked to the reduction in the stability of the $\beta$-domain; however, it is unclear whether disruption of the domain interface region is a requirement for facile unfolding, or what the affect would be of a mutation that resulted in a comparable reduction in stability of the $\alpha$-domain.

\section{Implications for amyloid disease}

The formation of amyloid fibrils from lysozyme is thought to proceed through partial unfolding of the protein, localised primarily in the $\beta$-domain and the interfacial region of the $\alpha$-domain; this process enables self-association to occur by contact with another partially unfolded lysozyme molecule through the mutually unfolded regions of the polypeptide chain. The T70N mutation destabilises the native fold, but no transient and cooperative partial unfolding transition was detected for the T70N variant at $37^{\circ} \mathrm{C}$. At higher temperatures, the T70N variant $\left(47^{\circ} \mathrm{C}\right)$ and wild-type protein $\left(57^{\circ} \mathrm{C}\right)$ both undergo partial unfolding in a locally cooperative manner that is essentially identical with that seen at lower temperature for the amyloidogenic I56T and D67H variants. These observations demonstrate that this unfolding beha- viour is an intrinsic property of the lysozyme fold, with an increase in the rate of partial unfolding linked to a decrease in native state stability. This suggests that under physiological conditions the amyloidogenic variants have a higher population of partially unfolded species than the T70N variant, which in turn has a higher population than the wild-type protein. Moreover, the I56T and wildtype lysozymes have been found to form partially unfolded species at low $\mathrm{pH}^{14}$ These partially unfolded forms are characterised by a loss of tertiary structure preceding the loss of secondary structure, and are stable at equilibrium rather than being a transient species; however, a lower temperature is needed to form such a state for the I56T variant than for the wild-type protein. Taken together, these findings indicate that mutations that destabilise the native state of lysozyme reduce the severity of the conditions required to populate a partially unfolded state, rather than generate new states that are inaccessible to the wild-type protein. Under physiological conditions, the T70N variant and even the wild-type protein are likely to populate partially unfolded states analogous to those identified for the amyloidogenic variants, but at much lower levels.

In order for such an intermediate state of this nature to be detected in hydrogen exchange mass spectrometry experiments, of the type described here, the rate of unfolding to form the intermediate must be fast enough relative to the rate of hydrogen exchange occurring through minor fluctuations in the native state, to allow hydrogen exchange to occur through the cooperative unfolding transition. Under such conditions, hydrogen exchange taking place as a result of the cooperative unfolding transition can be detected, as any exchangeable hydrogen atoms will be labelled irreversibly by their first exchange-competent opening transition. If, however, the rate of the cooperative unfolding process is slow compared to the rate of local fluctuations, the observed rate of hydrogen exchange will be dominated by the rate of exchange arising from the minor fluctuations in the native state. Therefore, any very slow partial unfolding process, even if they were occurring, would be obscured and undetectable in experiments of this type.

In contrast to the situation at $\mathrm{pH} 8$, the intrinsic rate of hydrogen exchange at $\mathrm{pH} 5$ is much slower than the rate of protein refolding, with hydrogen exchange occurring through an EX2 mechanism. ${ }^{12}$ Hence, the protection factors for any residues exchanging solely through partial unfolding will be equal to the equilibrium constant linking the partially unfolded and native states. ${ }^{12}$ Residues 53 , $54,55,58,59,61$ and 65 in the core of the $\beta$-domain of human lysozyme are highly protected in the wild-type protein, but are known to exchange via the locally cooperative partial unfolding process described above in the I56T and $\mathrm{D} 67 \mathrm{H}$ variants. ${ }^{8,12}$ The protection factors for these residues were averaged to give an equilibrium constant for the 
unfolding of the $\beta$-domain for the I56T and D67H variants. In the case of the $T 70 \mathrm{~N}$ variant, however, these residues are not exchanging solely through partial unfolding of the protein. Thus the observed rate of hydrogen exchange gives only an equilibrium constant corresponding to the maximum possible population of the intermediate. (The maximum rate of hydrogen exchange arising through cooperative unfolding is equal to the observed rate of hydrogen exchange.) It should be noted, however, that the actual population of the intermediate for the T70N variant is lower than the maximum possible population, with the difference being dependent upon the relative contributions of local and partial unfolding to hydrogen exchange. The $\mathrm{D} 67 \mathrm{H}$ and $\mathrm{I} 56 \mathrm{~T}$ variants have a calculated equilibrium constant of 4370 and 4460, respectively, indicating that approximately one molecule in 4500 molecules is in a partially unfolded state at $37^{\circ} \mathrm{C}$. The average of the protection factors for the T70N variant is, however, ca $1.8 \times 10^{5}$ at $37^{\circ} \mathrm{C}$, a value that is approximately 40 times greater than that for the I56T and $\mathrm{D} 67 \mathrm{H}$ variants. These findings indicate that the $T 70 \mathrm{~N}$ variant has a population of the partially unfolded state that is at least 40 times less than that of the amyloidogenic variants at physiological temperature. The probability of a partially unfolded aggregation-prone molecule encountering another such molecule will therefore be decreased by a factor of at least 1600 .

The present study shows, therefore, that the rates of aggregation of the variant proteins in vitro correlate with the decrease in the native state stabilities caused by the mutations, with that of the $T 70 \mathrm{~N}$ variant being intermediate between the I56T variant and the wild-type lysozyme. The decrease in the native state stability of the variant proteins results in an increase in the population of the aggregation-prone partially unfolded state. Previous studies of the kinetics of lysozyme amyloid fibril formation in vitro, suggests that this process takes place through a nucleation-elongation mechanism. ${ }^{7,8}$ In such a process, the nucleation step is thought to involve self-association of protein molecules through unfolded regions of the polypeptide chain, while fibril elongation depends on the condensation of partially unfolded molecules onto the fibrillar species. ${ }^{13}$ If this mechanism holds in vivo, a reduction in the concentration of partially unfolded molecules would both prolong the nucleation phase and retard fibril elongation, thereby inhibiting the aggregation process and decreasing the risk of amyloid disease.

Despite the destabilisation of its native state as a result of the mutation, the T70N variant of human lysozyme has not been identified in any amyloid deposits in vivo, suggesting that under normal conditions the population of partially unfolded molecules is below the threshold level required for the accumulation of protein aggregates in tissue; the T70N variant does, however, partially unfold significantly more readily than the wild-type protein, suggesting that it is more susceptible to fibrillar aggregation. In the case of transthyretin (TTR), a protein involved in another hereditary amyloidosis, destabilising mutations cause earlyonset amyloid disease, but wild-type TTR also aggregates in vivo to cause late-onset amyloidosis. Indeed, relatively minor amyloid deposits containing TTR are common in people over the age of 80 years. ${ }^{24,25}$ It is therefore possible to envisage that T70N lysozyme amyloidosis could occur as a lateonset disease as result of physiological stress, or that co-deposition of T70N lysozyme in amyloid deposits could increase the severity of amyloidoses, primarily caused by the aggregation of another protein. Although deposits containing T70N (or indeed wild-type) lysozyme have not been reported, it will be interesting to examine in greater detail whether or not such a situation could occur under at least some circumstances.

\section{Materials and Methods}

\section{Preparation of T70N mutant}

The wild-type human lysozyme gene was inserted into a pPIC9 expression vector (Invitrogen). The T70N mutation was introduced using LDA-PCR, ${ }^{26}$ with phosphorylated primers 5'-ACGGTAAGAACCCAGGCG CCGTTA- $3^{\prime}$, and $5^{\prime}$-GCATTCTGACATCCTCTTGAT TAGA- $3^{\prime}$, and its presence was confirmed by DNA sequencing. The pPIC9 plasmid containing the T70N lysozyme gene was linearised by digestion with StuI. Transformation into Pichia pastoris GS115 was performed using a Biorad micropulser electroporation apparatus. The cells were then plated on regeneration dextrose (RD) agar plates (Invitrogen) to produce single-clone colonies, which were screened for lysozyme activity with a hydrolase activity assay using Micrococcus lysodeikticus cells as the substrate. ${ }^{27}$

\section{Typical protein expression}

Buffered minimal glycerol (BMG) precultures $(3 \times$ $6 \mathrm{ml}$ ) in $50 \mathrm{ml}$ Falcon tubes were inoculated with P. pastoris cells containing the T70N lysozyme gene. To increase aeration of the precultures, the tubes were tilted by $45^{\circ}$ and shaken in an orbital incubator at $230 \mathrm{rpm}$ for $36 \mathrm{~h}$ at $30^{\circ} \mathrm{C}$. Aliquots $(2 \mathrm{ml})$ of the preculture cell suspension were used to inoculate $200 \mathrm{ml}$ of BMG medium in 21 Erlenmeyer flasks. The cultures were incubated at $30^{\circ} \mathrm{C}$ and $230 \mathrm{rpm}$ for $28 \mathrm{~h}$ then centrifuged in sterile centrifuge bottles at $1500 \mathrm{~g}$ for $5 \mathrm{~min}$. The supernatant was decanted off and the cells resuspended in $400 \mathrm{ml}$ of buffered minimal methanol (BMM) to induce protein expression. The BMM suspensions were incubated at $30^{\circ} \mathrm{C}$ and $230 \mathrm{rpm}$. Every $24 \mathrm{~h}, 2 \mathrm{ml}$ of methanol was added to the culture. After $72 \mathrm{~h}$, the methanolcontaining cultures were centrifuged at $1500 \mathrm{~g}$ at $4{ }^{\circ} \mathrm{C}$ for $5 \mathrm{~min}$. The supernatant was kept at $4{ }^{\circ} \mathrm{C}$, filtered at $0.45 \mu \mathrm{m}$ pore size, then purified using a cation-exchange (Poros $20 \mathrm{HS}$ ) column (Applied Biosystems, UK) on a Biocad 700E system (Applied Biosystems, UK). T70N lysozyme was eluted from the column by a linear gradient of $\mathrm{NaCl}$ solution $(0-1 \mathrm{M})$. Fractions were analysed by SDS-PAGE and those containing only lysozyme were combined, dialysed against water and 
lyophilised. The concentration of lysozyme was determined by measuring the absorbance at $280 \mathrm{~nm}$, using $E_{280}^{1 \%}$ for $1 \mathrm{~cm}$ path-length $=25.5 .^{13}$ The protein mass was analysed by electrospray ionisation time-of-flight (ESI-TOF) mass spectrometry (T70N, calc. 14,706 Da, obs. $14,707( \pm 1) \mathrm{Da}$; wild-type, calc. $14,693 \mathrm{Da}$, obs. $14,693( \pm 1) \mathrm{Da})$.

${ }^{15} \mathrm{~N}$-labelled protein was prepared either as described ${ }^{28}$ (I56T, wild-type) or expressed in P. pastoris (T70N, wildtype) with $200 \mathrm{ml}$ of $\mathrm{Fm} 22$ glycerol medium $(42.87 \mathrm{~g}$ of $\mathrm{KH}_{2} \mathrm{PO}_{4}, 5 \mathrm{~g}$ of $\left(\mathrm{NH}_{4}\right) \mathrm{SO}_{4}, 0.5 \mathrm{~g}$ of $\mathrm{CaSO}_{4}, 14.28 \mathrm{~g}$ of $\mathrm{K}_{2} \mathrm{SO}_{4}, 6 \mathrm{~g}$ of $\mathrm{MgSO}_{4}, 1 \mathrm{ml}$ of PTM1 salt solution, $800 \mu \mathrm{g}$ of biotin, $100 \mathrm{ml}$ of glycerol, adjusted to 11 with water, and to $\mathrm{pH} 6$ with $\mathrm{KOH}$ ) to build cell mass, and $400 \mathrm{ml}$ of Fm22 methanol medium $\left(42.87 \mathrm{~g}\right.$ of $\mathrm{KH}_{2} \mathrm{PO}_{4}, 5 \mathrm{~g}$ of $\left({ }^{15} \mathrm{NH}_{4}\right) \mathrm{SO}_{4}, 0.5 \mathrm{~g}$ of $\mathrm{CaSO}_{4}, 14.28 \mathrm{~g}$ of $\mathrm{K}_{2} \mathrm{SO}_{4}, 6 \mathrm{~g}$ of $\mathrm{MgSO}_{4}, 1 \mathrm{ml}$ of PTM1 salt solution, $800 \mu \mathrm{g}$ of biotin, $50 \mathrm{ml}$ of methanol, adjusted to 11 with water, and to $\mathrm{pH} 6$ with $\mathrm{KOH})$ to induce protein expression. The resulting ${ }^{15} \mathrm{~N}$-labelled protein was purified as described above for the unlabelled protein.

\section{X-ray crystallography}

Crystals were grown using the hanging-drop, vapourdiffusion method at $293 \mathrm{~K}$. A sample $(2 \mu \mathrm{l})$ of lysozyme solution $(10 \mathrm{mg} / \mathrm{ml}$ of protein, $10 \mathrm{mM}$ Hepes $(\mathrm{pH} 7.5)$, $0.4 \mathrm{M} \mathrm{LiCl})$ was mixed in a ratio of $1: 1(\mathrm{v} / \mathrm{v})$ with the reservoir solution $(20 \mathrm{mM}$ sodium acetate $(\mathrm{pH} 4.5), 2.5 \mathrm{M}$ $\mathrm{NaCl}$ ). Small, predominately rod-shaped crystals grew over a period of several weeks, which were unsuitable for structure determination; however, a single, larger crystal was formed. This crystal was flash-frozen in a nitrogen stream using a cryo-protectant of $25 \%(\mathrm{v} / \mathrm{v})$ glycerol in reservoir solution. Diffraction data were collected with $1^{\circ}$ oscillations, at $100 \mathrm{~K}$, using an MSC R-axis II image plate and Rigaku RU200 rotating anode $X$-ray generator and an osmic mirror $(\lambda=1.5418 \AA$ ). Diffraction intensities were integrated out to $2.5 \AA$ with the computer program Denzo and scaled with Scalepack (Table 1). ${ }^{29}$ The crystal space group was $P 2{ }_{1} 22_{1}$ with unit cell dimensions $a=31.117 \AA$, $b=56.178 \AA, c=62.488 \AA$. Molecular replacement was carried out with $\mathrm{AMoRe},{ }^{30}$ using wild-type human lysozyme (PDB 1JSF) with residues 68-73 deleted as the search model. The structure was refined initially via repeated cycles of simulated annealing using $\mathrm{CNS}^{31}$ and manual rebuilding (QUANTA, Accelrys Inc. San Diego, USA), until the loop region in the vicinity of the mutation had settled into a consistent position. Subsequently, the structure was refined with restrained refinement using Refmac, $^{32}$ and solvent atoms were added. Refinement and manual rebuilding were continued until the atom positions were consistent and $R_{\text {free }}$ had stabilised (0.27). The quality of the stereochemistry was evaluated using PROCHECK, ${ }^{33}$ and the structure was solved independently using RAPPER to confirm there were no significant defects. ${ }^{34}$

\section{NMR spectroscopy}

A ${ }^{15} \mathrm{~N}$-labelled T70N sample was prepared in a Shigemi tube by dissolving $3.7 \mathrm{mg}$ of ${ }^{15} \mathrm{~N}$-labelled protein in $400 \mu \mathrm{l}$ of $90 \% \mathrm{H}_{2} \mathrm{O}, 10 \%{ }^{2} \mathrm{H}_{2} \mathrm{O}$ and adjusted to $\mathrm{pH} 5.0$. Assignment of ${ }^{15} \mathrm{~N}$ heteronuclear single quantum coherence (HSQC) spectra of T70N lysozyme at $37^{\circ} \mathrm{C}$ was conducted initially using the assignments for the wild-type protein (G.L. et al., unpublished results). ${ }^{35}$ Unassigned residues were then assigned using 3D HSQC- total correlated spectroscopy (TOCSY) and 3D HSQCNOESY spectra. ${ }^{1} \mathrm{H}$ and ${ }^{15} \mathrm{~N}$ chemical shifts were determined from an HSQC spectrum recorded at $37^{\circ} \mathrm{C}$ with 32 transients, 1024 complex points in $t_{2}$ and 256 in $t_{1}$, and sweep widths of $8389 \mathrm{~Hz}$ in $F_{2}, 2554 \mathrm{~Hz}$ in $F_{1}$ on a Bruker Avance $700 \mathrm{MHz}$ NMR spectrometer equipped with a TXI probe.

${ }^{15} \mathrm{~N} T_{1}, T_{2}$ and NOE relaxation data were recorded at $37^{\circ} \mathrm{C}$ on a Bruker Avance $500 \mathrm{MHz}$ NMR spectrometer. The NOE and NONOE experiments were recorded in an interleaved fashion with a relaxation delay of $5 \mathrm{~s}, 56$ transients, 1024 complex points in $t_{2}$, and 124 in $t_{1}$ and with sweep widths of $7508 \mathrm{~Hz}$ in $F_{2}, 1824 \mathrm{~Hz}$ in $F_{1}$. The $T_{1}$ and $T_{2}$ experiments were recorded with 16 transients $\left(T_{1}\right)$ and 32 transients $\left(T_{2}\right), 1024$ complex points in $t_{2}$ and 128 in $t_{1}$, and sweep widths of $7042 \mathrm{~Hz}$ in $F_{2}, 3846 \mathrm{~Hz}$ in $F_{1}$. (T delays in ms, 15.96, 1596, 31.93, 798.2, 47.89, 598.7, 79.82, $478.94,119.74,359.2,199.6$, and 279.38$)$; $\left(T_{2}\right.$ delays in $\mathrm{ms}$, 7, 14, 28, 42, 56, 70, 84, 140, 119, 161, 203, 245, and 294).

All spectra were processed with NMRPipe, ${ }^{36}$ and viewed with Sparky ${ }^{\dagger}$ or NMRView. ${ }^{37}$ Relaxation and exchange rates were fit to a two-parameter, singleexponential decay with nmrView. Analysis of relaxation parameters was carried out with the extended model-free formulism $^{18-20}$ in Modelfree, ${ }^{21}$ using a chemical shift anisotropy for an amide ${ }^{15} \mathrm{~N}$ nucleus of $-160 \mathrm{ppm}$ and a $\mathrm{N}-\mathrm{HN}$ bond length of $1.02 \AA$. The data were fit using an isotropic model with a rotational correlation time of $4.7 \mathrm{~ns}$.

\section{Real time H/D measurements}

Lysozyme samples (T70N/WT) were dissolved in $550 \mu \mathrm{l}$ of $20 \mathrm{mM} \mathrm{D}-4$ acetic acid in ${ }^{2} \mathrm{H}_{2} \mathrm{O}$ pD 5 . The sample was immediately placed in the Bruker Avance $700 \mathrm{MHz}$ NMR spectrometer pre-tuned and shimmed with an equivalent sample. A series of HSQC spectra were recorded with eight transients, 1084 complex points in $t_{2}, 96$ in $t_{1}$ and sweep widths of $7042 \mathrm{~Hz}$ in $F_{2}$ and $2199 \mathrm{~Hz}$ in $F_{1}$. Hydrogen exchange rates were measured from the reduction of peak volume over time. Protection factors were calculated from the ratio of experimental rates to the predicted rates for a random coil model based on the primary structure. ${ }^{16}$

\section{Mass spectrometry}

${ }^{15} \mathrm{~N}$-labelled I56T, unlabelled T70N, unlabelled wildtype and ${ }^{15} \mathrm{~N}$-labelled wild-type lysozymes were deuterated at exchangeable sites by unfolding in guanidinium chloride (predeuterated by three cycles of dissolution in ${ }^{2} \mathrm{H}_{2} \mathrm{O}$ followed by lyophilisation) in ${ }^{2} \mathrm{H}_{2} \mathrm{O}$. The proteins were refolded via dilution in ${ }^{2} \mathrm{H}_{2} \mathrm{O}$ and subsequently concentrated. Cycles of dilution and concentration in ${ }^{2} \mathrm{H}_{2} \mathrm{O}$ were repeated until no guanidinium ion contamination was observed in mass spectra of lysozyme. For comparative experiments, solutions with an equal concentration of T70N and ${ }^{15} \mathrm{~N}$-labelled wild-type, or T70N and ${ }^{15} \mathrm{~N}$-labelled I56T lysozyme, were prepared before the initiation of hydrogen exchange. The final concentration of protein in each experiment was $8 \mu \mathrm{M}$ for each constituent. Samples were prepared by manual mixing of $20 \mu \mathrm{l}$ of protein solution with $300 \mu \mathrm{l}$ of pulse-labelling buffer (100 mM ammonia/formic acid ( $\mathrm{pH} 8)$, in $\mathrm{H}_{2} \mathrm{O}$ ) at $37^{\circ} \mathrm{C}$ for various lengths of time $(0.5 \mathrm{~s}-1 \mathrm{~h})$ followed by quenching with $140 \mu \mathrm{l}$ of $1 \mathrm{M}$ acetic acid. After quenching,

$\dagger$ http://www.cgl.ucsf.edu/home/sparky/ 
the solution ( $\mathrm{pH}$ 3.5) was placed on ice and analysed immediately by mass spectrometry. A fully exchanged sample was prepared by incubating the protein in the pulse-labelling buffer for $15 \mathrm{~min}$ at $80^{\circ} \mathrm{C}$ prior to quenching. No adjustment has been made to the total number of exchanged hydrogen atoms for the $6 \%$ deuterium present in the pulse solutions. Mass spectra of pulse-labelled samples were recorded using a Micromass LC-ToF spectrometer (Micromass) with cone voltage of $80 \mathrm{~V}$ as described. ${ }^{12}$ For each experiment, $2 \mu \mathrm{l}$ of protein solution was used and the mass spectra shown (Figure 5) represent the convolution of $+7,+8,+9$ charge states with minimal smoothing and converted to a mass scale. Rates of partial unfolding were calculated from variations in peak intensity over time.

\section{Circular dichroism}

T70N or wild-type human lysozyme was dissolved in $10 \mathrm{mM}$ sodium acetate $(\mathrm{pH} 5.0)$ and filtered at $0.22 \mu \mathrm{m}$ pore size. The protein was diluted to a final concentration of $0.2 \mathrm{mg} / \mathrm{ml}$ and overlaid with mineral oil. Spectra were recorded at $270 \mathrm{~nm}$ with a $10 \mathrm{~mm}$ path-length cuvette. Thermal unfolding was monitored between $20^{\circ} \mathrm{C}$ and $97^{\circ} \mathrm{C}$ with a temperature increase of $0.5 \mathrm{deg}$. C/min. Ellipticity values were normalised to the fraction of unfolded molecules $\left(F_{\mathrm{u}}\right)$ using $F_{\mathrm{u}}=\left(\theta-\theta_{\mathrm{N}}\right) /\left(\theta_{\mathrm{U}}-\theta_{\mathrm{N}}\right)$, where $\theta$ is observed ellipticity, $\theta_{N}$ is native ellipticity and $\theta_{\mathrm{U}}$ is unfolded ellipticity. $\theta_{\mathrm{N}}$ and $\theta_{\mathrm{U}}$ were obtained by extrapolation from the pre and post-transition baselines at the relevant temperature. Curve fitting was carried out with Kaleidagraph (v3.51, Synergy software, Reading PA)

\section{Aggregation kinetics}

Stock solutions of the proteins were filtered at $0.22 \mu \mathrm{m}$ pore size and diluted to a final concentration of $0.1 \mathrm{mg} /$ $\mathrm{ml}$ of protein in $0.1 \mathrm{M}$ tri-sodium citrate buffer $(\mathrm{pH} 5.5)$ containing $3 \mathrm{M}$ urea. Samples were incubated at $48{ }^{\circ} \mathrm{C}$, with stirring, in a Cary Eclipse spectrofluorimeter and shaken every $20 \mathrm{~min}$ to ensure dispersion of protein aggregates. Protein aggregation was monitored through changes in the fluorescence emission at $500 \mathrm{~nm}$; the excitation wavelength was $500 \mathrm{~nm}$, and excitation and emission slit-widths were $5 \mathrm{~nm}$.

\section{Protein Data Bank accession numbers}

The crystallographic coordinates and structure factors have been deposited in the Protein Data Bank (PDB file 1W08, 1W08SF).

\section{Acknowledgements}

The authors are grateful to Vittorio Bellotti for helpful discussions on the properties of T70N lysozyme and to Trevor Rutherford for assistance with the relaxation experiments. R.J.K.J. is supported by a BBSRC studentship, J.C. is supported by a Wellcome Trust International Prize Travelling Fellowship, J.R.K. is supported by an NSERC (Canada) postdoctoral fellowship and G.L. is supported by a fellowship from the Wenner-Gren
Fondations. The research of B.L. is supported by the Wellcome Trust. The research of C.M.D. is supported, in part, by Programme Grants from the Wellcome Trust and the Leverhulme Trust. This work was supported also by a grant from BBSRC (to D.B.A., C.M.D. and C.V.R.) and the Belgian Government, under the framework of the Interuniversity Attraction Poles (IAP P5/33 to C.M.D.).

\section{References}

1. Pepys, M. B., Hawkins, P. N., Booth, D. R., Vigushin, D. M., Tennent, G. A. \& Soutar, A. K. (1993). Human lysozyme gene mutations cause hereditary systemic amyloidosis. Nature, 362, 553-557.

2. Yazaki, M., Farrell, S. A. \& Benson, M. D. (2003). A novel lysozyme mutation Phe57Ile associated with hereditary renal amyloidosis. Kidney Int. 63, 16521657.

3. Valleix, S., Drunat, S., Philit, J., Adoue, D., Piette, J., Droz, D. et al. (2002). Hereditary renal amyloidosis caused by a new variant lysozyme W64R in a French family. Kidney Int. 61, 907-912.

4. Artymiuk, P. J. \& Blake, C. C. F. (1981). Refinement of human lysozyme at $1.5 \AA$ resolution. Analysis of non bonded and hydrogen bonded interactions. J. Mol. Biol. 152, 737-762.

5. Booth, D. R., Pepys, M. B. \& Hawkins, P. N. (2000). A novel variant of human lysozyme (T70N) is common in the normal population. Hum. Mutat. 16, 180-181.

6. Esposito, G., Garcia, J., Mangione, P., Giorgetti, S., Corazza, A., Viglino, P. et al. (2003). Structural and folding dynamic properties of the T70N variant of human lysozyme. J. Biol. Chem. 278, 25910-25918.

7. Dumoulin, M., Last, A. M., Desmyter, A., Decanniere, K., Canet, D., Larsson, G. et al. (2003). A camelid antibody fragment inhibits the formation of amyloid fibrils by human lysozyme. Nature, 424, 783-788.

8. Dumoulin, M., Canet, D., Last, A. M., Archer, D. B., Muyldermans, S., Wyns, L. et al. (2005). Reduced global cooperativity is a common feature underlying the amyloidogenicity of pathogenic lysozyme mutations. J. Mol. Biol. 346, 773-788.

9. Harper, J. D. \& Lansbury, P. T., Jr (1997). Models of amyloid seeding in Alzheimer's disease and scrapie: mechanistic truths and physiological consequences of the time-dependent solubility of amyloid proteins. Annu. Rev. Biochem, 66, 385-407.

10. Serio, T. R., Cashikar, A. G., Kowal, A. S., Sawicki, G. J., Moslehi, J. J., Serpell, L. et al. (2000). Nucleated conformational conversion and the replication of conformational information by a prion determinant. Science, 289, 1317-1321.

11. Thirumalai, D., Klimov, D. K. \& Dima, R. I. (2003). Emerging ideas on the molecular basis of protein and peptide aggregation. Curr. Opin. Struct. Biol. 13, 146159.

12. Canet, D., Last, A. M., Tito, P., Sunde, M., Spenser, A., Archer, D. B. et al. (2002). Local cooperativity in the unfolding of an amyloidogenic variant of human lysozyme. Nature Struct. Biol. 9, 308-315.

13. Booth, D. R., Sunde, M., Bellotti, V., Robinson, C. V., Hutchinson, W. L., Fraser, P. E. et al. (1997). Instability, unfolding and aggregation of human lysozyme variants underlying amyloid fibrillogenesis. Nature, 385, 787-793.

14. Morozova-Roche, L. A., Zurdo, J., Spenser, A., Noppe, 
W., Receveur, V., Archer, D. B. et al. (2000). Amyloid fibril formation and seeding by wild-type human lysozyme and its disease-related mutational variants. J. Struct. Biol. 130, 339-351.

15. Chamberlain, A. K., Receveur, V., Spencer, A., Redfield, C. \& Dobson, C. M. (2001). Characterization of the structure and dynamics of amyloidogenic variants of human lysozyme by NMR spectroscopy. Protein Sci. 10, 2525-2530.

16. Bai, Y., Milne, J. S., Mayne, L. \& Englander, S. W. (1993). Primary structure effects on peptide group hydrogen exchange. Proteins: Struct. Funct. Genet. 17, $75-86$.

17. Mine, S., Udea, T., Hashimoto, Y. \& Imoto, T. (2000). Analysis of the internal motion of free and ligandbound human lysozyme by use of ${ }^{15} \mathrm{~N}$ NMR relaxation measurement: a comparison with those of hen lysozyme. Protein Sci. 9, 1669-1684.

18. Lipari, G. \& Szabo, A. (1982). Modelfree approach to the interpretation of nuclear magnetic resonance relaxation in macromolecules. 1 . Theory and range of validity. J. Am. Chem. Soc. 104, 4546-4559.

19. Lipari, G. \& Szabo, A. (1982). Modelfree approach to the interpretation of nuclear magnetic resonance relaxation in macromolecules. 2. Analysis of experimental results. J. Am. Chem. Soc. 104, 4559-4570.

20. Clore, G. M., Szabo, A., Bax, A., Kay, L. E., Driscoll, P. C. \& Gronenborn, A. M. (1990). Deviations from the simple two-parameter model-free approach to the interpretation of nitrogen-15 nuclear magnetic relaxation of proteins. J. Am. Chem. Soc. 112, 4989-4991.

21. Mandel, A. M., Akke, M. \& Palmer, A. G., III (1995). Backbone dynamics of Escherichia coli ribonuclease HI: correlations with structure and function in an active enzyme. J. Mol. Biol. 246, 144-161.

22. Itzhaki, L. S., Otzen, D. E. \& Fersht, A. R. (1995). The structure of the transition state for folding of chymotrypsin inhibitor 2 analysed by protein engineering methods: evidence for a nucleation-condensation mechanism for protein folding. J. Mol. Biol. 254, 260-288.

23. Otzen, D. E., Itzhaki, L. S., elMasry, N. F., Jackson, S. E. \& Fersht, A. R. (1994). Structure of the transition state for the folding/unfolding of the barley chymotrypsin inhibitor 2 and its implications for mechanisms of protein folding. Proc. Natl Acad. Sci. USA, 91, 1042210425.

24. Westermark, P., Sletten, K., Johansson, B. \& Cornwell, G. G., III (1990). Fibril in senile systemic amyloidosis is derived from normal transthyretin. Proc. Natl Acad. Sci. USA, 87, 2843-2845.
25. Pepys, M. B. (2001). Pathogenesis, diagnosis and treatment of systemic amyloidosis. Phil. Trans. Roy. Soc. ser. B, 356, 203-211.

26. Chen, Z. \& Ruffner, D. E. (2002). Amplification of closed circular DNA in vitro. Nucl. Acids Res. 26, $1126-1127$.

27. Lee, Y. C. \& Yang, D. (2002). Determination of lysozyme activities in a microplate format. Anal. Biochem. 310, 223-224.

28. Spencer, A., Morozova-Roche, L. A., Noppe, W., MacKenzie, D. A., Jeenes, D. J., Joniau, M. et al. (1999). Expression, purification, and chracterisation of the recombinant calcium binding equine lysozyme secreted by the filamentous fungus, Aspergillus niger. Comparisons with the production of hen and human lysozymes. Protein Expr. Purif. 16, 171-180.

29. Otwinoski, Z. \& Minor, W. (1997). Processing of X-ray diffraction data collected in oscillation mode. Methods Enzymol. 276, 307-326.

30. Navaza, J. (1994). AMoRe: an automated package for molecular replacement. Acta Crystallog. sect. A, 50, 157-163.

31. Brünger, A. T., Adams, P. D., Clore, G., DeLano, W. L., Gros, P., Grosse-Kunstleve, R. W. et al. (1998). Crystallography \& NMR system: a new software suite for macromolecular structure determination. Acta Crystallog. sect. D, 54, 905-921.

32. Murshudov, G. N., Vagin, A. A. \& Dodson, E. J. (1997). Refinement of macromolecular structures by the maximum-likelihood method. Acta Crystallog. sect. D, 53, 240-255.

33. Laskowski, R. A., MacArthur, M. W., Moss, D. S. \& Thornton, J. M. (1993). PROCHECK: a program to check the stereochemical quality of protein structures. J. Appl. Crystallog. 26, 283-291.

34. DePristo, M. A., de Bakker, P. I. W., Johnson, R. J. K. \& Blundell, T. L. (2005). Crystallographic refinement by knowledge-based exploration of complex energy landscapes. Structure. In the press.

35. Ohkubo, T., Taniyama, Y. \& Kikuchi, M. (1991). ${ }^{1} \mathrm{H}$ and ${ }^{15} \mathrm{~N}$ NMR study of human lysozyme. J. Biochem. (Tokyo), 110, 1022-1029.

36. Delaglio, F., Grzesiek, S., Vuister, G. W., Zhu, G., Pfeifer, J. \& Bax, A. (1995). NMRPipe: a multidimensional spectral processing system based on UNIX pipes. J. Biomol. NMR, 6, 277-293.

37. Johnson, B. A. \& Blevins, R. A. (1994). NMRView: a computer program for the visualization and analysis of NMR data. J. Biol. NMR, 4, 603.

38. Koradi, R., Billeter, M. \& Wüthrich, K. (1996). MOLMOL: a program for display and analysis of macromolecular structures. J. Mol. Graph. 14, 51-55.

Edited by A. G. Palmer III

(Received 31 March 2005; received in revised form 6 July 2005; accepted 12 July 2005) Available online 27 July 2005 